\title{
Perancangan Augmented Reality (AR) Sebagai Media Promosi Objek Wisata Berbasis Android
}

\author{
Arsy Febrina Dewi ${ }^{*}$, M. Ikbal ${ }^{2}$ \\ 1Program Studi Teknologi Rekayasa Instrumentasi dan Kontrol, Politeknik Negeri Lhokseumawe \\ 2Program Studi Teknik Informatika, Universitas Islam Kebangsaan Indonesia \\ *arsyfebrinadw@pnl.ac.id
}

\begin{abstract}
Abstrak
Pariwisata merupakan salah satu hal yang penting bagi suatu daerah. Wisata yang menarik dan ramai dikunjungi menunjukkan kemajuan daerah tersebut. Salah satu cara memajukan pariwisata adalah dengan media promosi. Banyak cara yang dapat digunakan untuk promosi, salah satunya dengan memanfaatkan teknologi informasi berbasis Augmented Reality (AR). AR adalah teknologi yang menampilkan objek virtual 3D ke dalam lingkungan nyata dan membangun visualisasi gambar 3D pada brosur tempat wisata menjadi lebih informatif. AR membantu pengguna mendapatkan informasi yang lebih jelas tentang objek wisata yang ingin dikunjungi di kota Langsa. Penggunaan AR pada android menjadikan sistem semakin mudah diakses oleh pengguna. Berdasarkan uji coba, sistem AR berhasil di terapkan pada sistem Android. Selain itu dilakukan juga uji coba kamera berdasarkan jarak, sudut kemiringan, dan pencahayaan pada saat mendeteksi marker objek wisata. Hasilnya adalah kamera berhasil mendeteksi image target (marker) dan memunculkan animasi 3D objek wisata. Namun hasil terbaik dalam mendeteksi marker adalah jarak diatas $15 \mathrm{~cm}$ dengan sudut dengan kriteria pencahayaan sinar matahari berawan.
\end{abstract}

Kata kunci: Augmented Reality (AR), Objek 3D, Android

\begin{abstract}
Tourism is one of the most important things for an area. Interesting and crowded tourism shows the progress of the area. One way to promote tourism is by media promotion. There are many ways that can be used for promotion, one of which is by utilizing information technology based on Augmented Reality (AR). AR is a technology that displays 3D virtual objects into a real environment and builds visualization of $3 \mathrm{D}$ images in tourist brochures to be more informative. AR helps users get clearer information about the attractions they want to visit in Langsa city. The use of AR on Android makes the system more accessible to users. Based on trials, the AR system was successfully implemented on the Android system. In addition, camera trials were also carried out based on distance, tilt angle, and lighting when detecting tourist attraction markers. The result is that the camera successfully detects the target image (marker) and generates a 3D animation of a tourist attraction. However, the best results in detecting markers are distances above $15 \mathrm{~cm}$ at an angle with cloudy sunlight lighting criteria.
\end{abstract}

Keywords: Augmented Reality (AR), 3D Object, Android

\section{Pendahuluan}

Pariwisata merupakan salah satu hal penting dalam dalam kemajuan suatu daerah. Kemajuan pariwisata tentunya harus di dukung dengan upaya promosi yang baik pula. Salah satu media promosi yang sering digunakan misalnya menggunakan media cetak [1]. Namun tidak dapat dipungkiri, perkembangan teknologi 
informasi saat ini, hampir merambah pada semua bidang, termasuk bidang promosi. Saat ini, hampir semua masyarakat bisa menggunakan Handphone. Kapasitas dan kemampuan Handphone juga semakin baik. Banyak fitu-fitur yang memudahkan manusia dalam mengakses informasi. Karena itu, media promosi menggunakan Handphone merupakan hal yang efektif saat ini. Salah satu metode efektif yang dapat digunakan sebagai media promosi berbasis Handphone adalah Augmented Reality (AR). Augmented Reality (AR) merupakan suatu teknologi yang memasukkan objek virtual 3D ke dalam lingkungan nyata. AR membangun visualisasi gambar 3D pada brosur tempat wisata menjadi lebih informatif, sehingga membantu pengguna mendapatkan informasi yang lebih jelas tentang objek wisata yang ingin dikunjungi. AR juga diterapkan pada android, agar pengguna lebih mudah mengakses informasi objek wisata yang ingin dilihat.

Penelitian ini menggunakan beberapa objek wisata yang banyak dikunjungi di kota Langsa, Aceh, yaitu Hutan Lindung, Lapangan Merdeka, bambu runcing, dan hutan mangrove. Sistem dirancang menggunakan software Unity, Photoshop dan SkecthUP yang mampu menampilkan objek wisata dalam bentuk 3D. Kamera akan mendeteksi marker objek wisata tertentu untuk menampilkan animasi 3D yang sesuai. Dengan menggunakan sistem ini diharapkan masyarakat dapat memperoleh infromasi jelas tentang objek wisata yang ingin dikunjungi baik di kota Langsa,maupun daerah lainnya sehingga tercipta promosi pariwisata yang efektif dan edukatif.

\section{Tinjauan Pustaka}

\subsection{Penelitian Terkait}

Benz Edi Kusuma dengan judul Analisa dan Perancangan Teknologi Augmented Reality Berbasis Android Dalam memberikan Petunjuk Navigasi Ruangan pada Universitas Pelita Harapan Medan" yang memanfaatkan AR sebagai penunjuk ruangan yang terdapat pada Universitas tersebut [2]. Penelitian yang dilakukan oleh Zwingly Ch Rawis, dkk, dengan judul " Penerapan Augmented Reality Berbasis Android Untuk mengenalkan Pakaian Adat Tountemboan" bertujuan memanfaatkan teknologi AR untuk memperkenalkan berbagai model pakaian Adat Tountemboan kepada masyarakat umum dan khususnya masyarakat Sulawesi Utara [3]. Penelitian Maurizka Zahra Devita yang berjudul "Augmented Reality Pengenalan Huruf dan Angka Arab Menggunakan Metode Marker Based Tracking Berbasis Android" yang bertujuan memudahkan pengenalan huruf hijaiyah dengan tampilan 3D [4]. Penelitian Ayu Fadhiratul Masrura dengan judul "Aplikasi Edukasi Berbasis Android menggunakan Augmented Reality yang menerapkan AR sebagai media pembelajaran 
sejarah agar lebih menarik [5]. Penelitian Mardiana dengan judul "Augmented Reality Pelacak Lokasi Pustaka dengan AR Marker", yang menggunakan AR Marker untuk membantu melacak dan menemukan lokasi koleksi Pustaka yang diperlukan pengunjung [6]. Sedangkan penelitian ini menggunakan $A R$ untuk media promosi wisata di kota Langsa Aceh. Sistem ini juga di uji coba dengan pengambilan dari sudut kamera dan intensitas cahaya yang berbeda untuk mengetahui kehandalan kinerja sistem pada Handphone pengguna.

\subsection{Landasan Teori}

1. Augmented Reality

Augmanted Reality (AR) adalah teknologi penggabungan benda maya dua dimensi atau tiga dimensi ke dalam sebuah lingkungan nyata tiga dimensi. Benda maya tersebut akan diproyeksikan dalam waktu nyata. [7].

2. Teknik Marker Based Tracking

Teknik Marker Based Tracking adalah salah satu teknik yang banyak digunakan dalam pengembangan AR. Metode kerja tenik ini adalah melacak marker melalui tiga sumbu $X$, $Y$ dan $Z$ serta bantuan titik koordinat $(0,0,0)$ secara virtual pada ruang 3 dimensi. Marker adalah gambar yang bisa diproses melalui video gambar dan teknologi image processing, pattern recoginition, dan computer vision. AR akan mendefinisikan skala yang benar melalui pose kamera, jika marker terdeteksi. Semakin bervariasi gambar, maka semakin banyak pola terbentuk. Ini memungkinkan marker akan mudah dilacak untuk menempatkan model citra yang akan di deteksi [5].

3. Unity $3 D$

Aplikasi Unity 3D adalah suatu software pengolah gambar, grafik, suara yang bisa digunakan untuk membuat game dan objek animasi. Objek 3D sering digunakan untuk simulasi yang memerlukan tampilan menarik. Unity semakin berkembang karena dapat digunakan secara free user dan dimplementasikan ke dalam berbagai platform [8].

4. Android

Android adalah suatu sistem operasi perangkat mobile berbasis Linux. Android menghadirkan platform terbuka bagi pengembang, sehingga memungkinkan untuk menciptakan aplikasi baru. Android merupakan generasi baru untuk platform mobile yang memberikan kemudahan bagi para pengembang untuk melakukan pengembangan sesuai yang diharapkan. Berdasarkan hal itu, android semakin banyak digunakan untuk memudahkan manusia dalam melakukan banyak hal. [15] 


\section{Metode Penelitian}

\subsection{Alur Penelitian}

Dalam merancang sistem ini terdapat beberapa hal yang harus dilakukan. Tahap awal adalah melakukan studi literature dan mendesain layout yang sesuai dengan objek wisata yang di teliti. Setelah semua resource dan layout dibuat, tahapan selanjutnya adalah melakukan konfigurasi dan pengkodean program. Berikut merupakan flowchart dan langkah-langkah penelitian yang dilakukan.

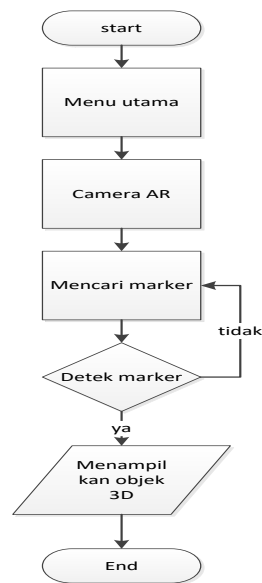

\section{Gambar 1. Flowchart Kamera}

Pada gambar 1 menjelaskan, aplikasi langsung menampilkan menu utama. Pada menu utama tersebut terdapat pilihan menu camera AR, Ketika memilih camera AR, maka aplikasi akan mengaktifkan kamera untuk proses pendeteksian marker dan menampikan objek 3D.

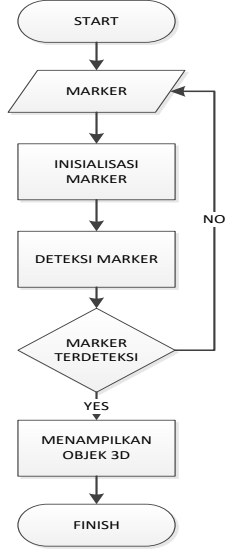

Gambar 2. Deteksi Marker

Gambar 2 menjelaskan proses pendeteksian marker dimulai dengan user menunjukkan marker pada kamera. Kemudian kamera akan mendeteksi marker tersebut. Keberhasilan kamera dalam mendeteksi marker bergantung pada beberapa kondisi, seperti intensitas cahaya, jarak marker dengan kamera, sudut posisi kamera. Jika marker tidak terdeteksi, maka user harus mengatur marker dan menunjukkan kembali pada kamera. Jika marker telah terdeteksi, maka aplikasi akan menampilkan objek 3D yang sesuai dengan dengan marker.

\subsection{Use Case Diagram}

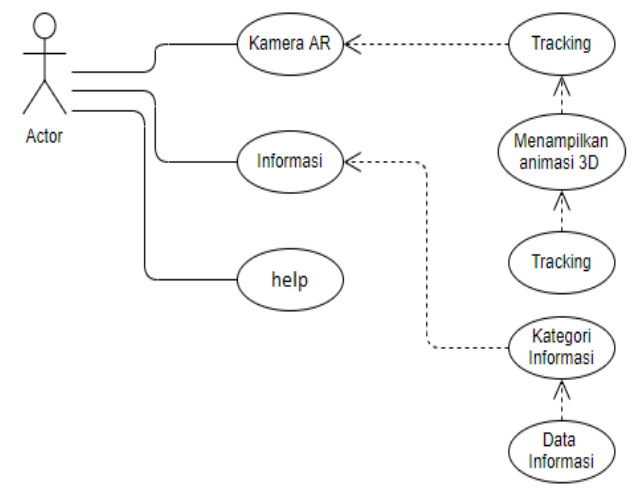

Gambar 3. Use Case Diagram 
Gambar 3 mendeskripsikan interaksi antara pengguna dengan aktifitas sistem. Pada gambar terlihat Aktor dapat mengakses kamera untuk menggunakan sistem dan dapat memperoleh infomasi yang di sediakan sistem.

\subsection{Perancangan Objek 3D}

Pembuatan objek 3D dilakukan dengan menggunakan Software SketchUp. Setelah itu langsung dilakukan pembuatan objek wisata dalam bentuk 3D. Model Objek tersebut di eksport menjadi ber ekstensi .fbx agar semua material yang telah dibuat menjadi satu paket saat objek diimport ke Unity.

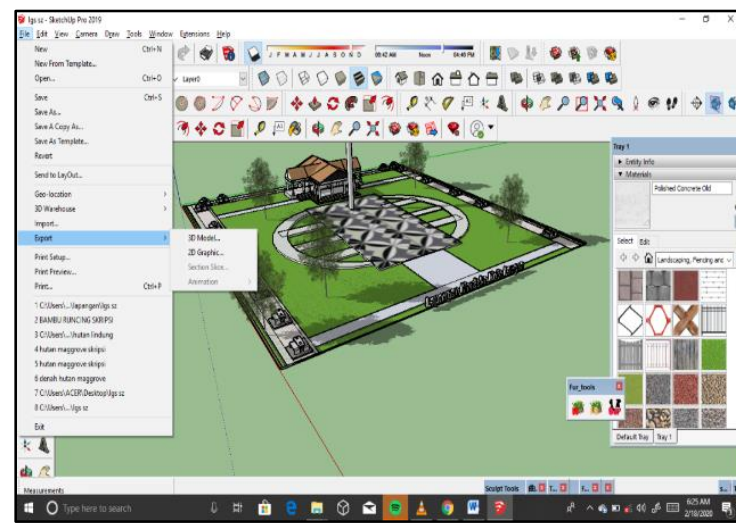

Gambar 4. Eksport Objek 3D

\subsection{Perancangan AR}

Pada sistem ini AR dibuat menggunakan software Unity 3D. Dalam pembuatannya diperlukan Vuforia SDK yang merupakan produk dari Qualcomm. Paket Vuforia SDK berisi librarylibrary yang berguna agar aplikasi dapat mengenal gambar sebagai marker. Marker pada sistem ini di desain menggunakan Photoshop. Selanjutnya marker diolah menjadi package marker yang dikenali dan dijadikan objek target.

\section{Hasil Dan Pembahasan}

\subsection{Tampilan Marker}

Marker merupakan gambar yang digunakan sebagai target dalam memunculkan objek pada sistem AR. Marker juga disebut image target [12]. Beberapa contoh gambar dibawah ini merupakan beberapa contoh marker yang akan digunakan dalam aplikasi Wisata berbasis Augmented Reality.

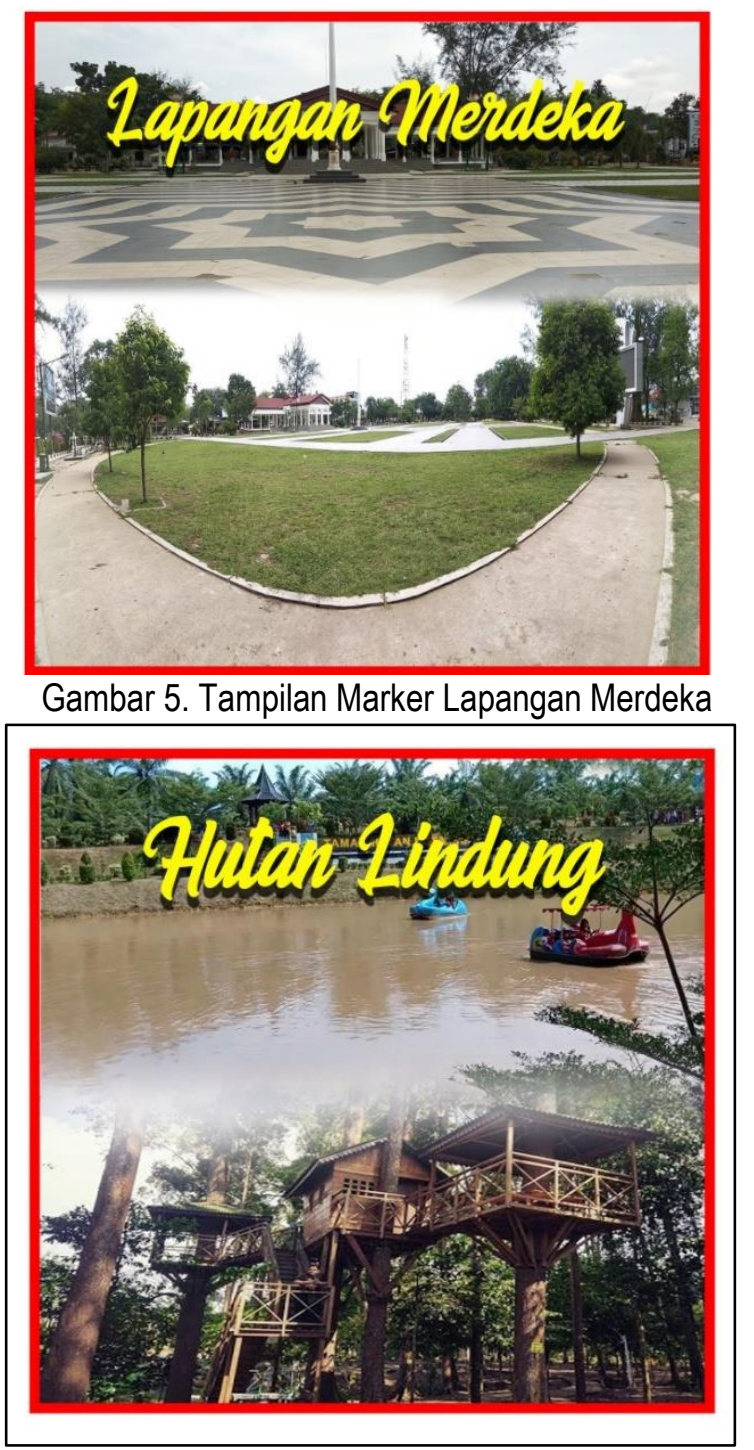

Gambar 6. Tampilan Marker Hutan Lindung 
Infotek : Jurnal Informatika dan Teknologi

Vol. 5 No. 1, Januari 2022

Hal. $179-186$

DOI : $10.29408 /$ jit.v5i1.4760

Link : https://dx.doi.org/10.29408/jit.v451.4760

\subsection{Tampilan Aplikasi}

Aplikasi terdiri dari halaman dan menu pertama yang muncul saat pertama membuka aplikasi, Pada sistem ini terdapat 4 menu utama yaitu Camera AR, Informasi, Help dan Keluar.

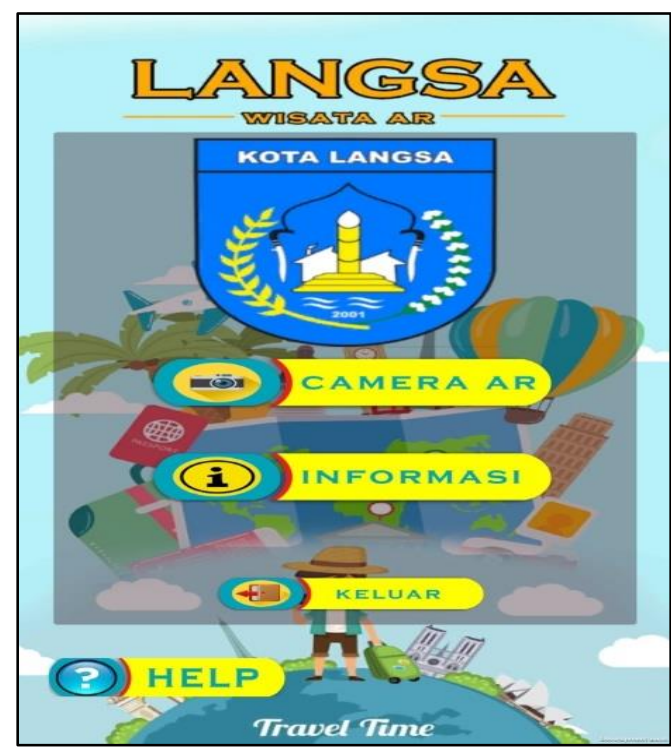

Gambar 7. Tampilan Halaman Utama

\subsection{Tampilan Kamera AR}

Tampilan Camera AR adalah halaman dimana menampilkan kamera dengan Augmented Reality, kamera dapat diarahkan ke marker yang akan menampilkan objek 3D sesuai dengan objek wisata yang diinginkan.

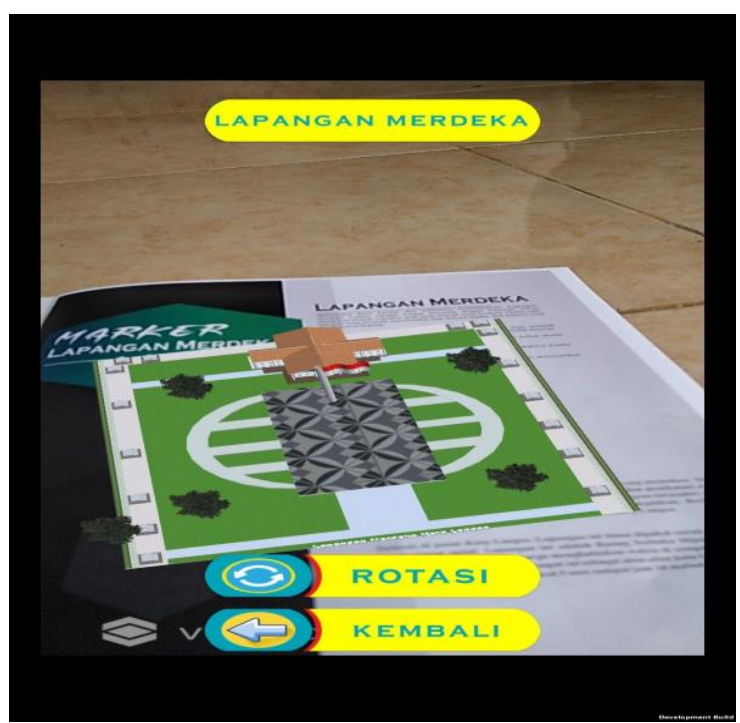

Gambar 8. Tampilan KameraObjek Lapangan Merdeka

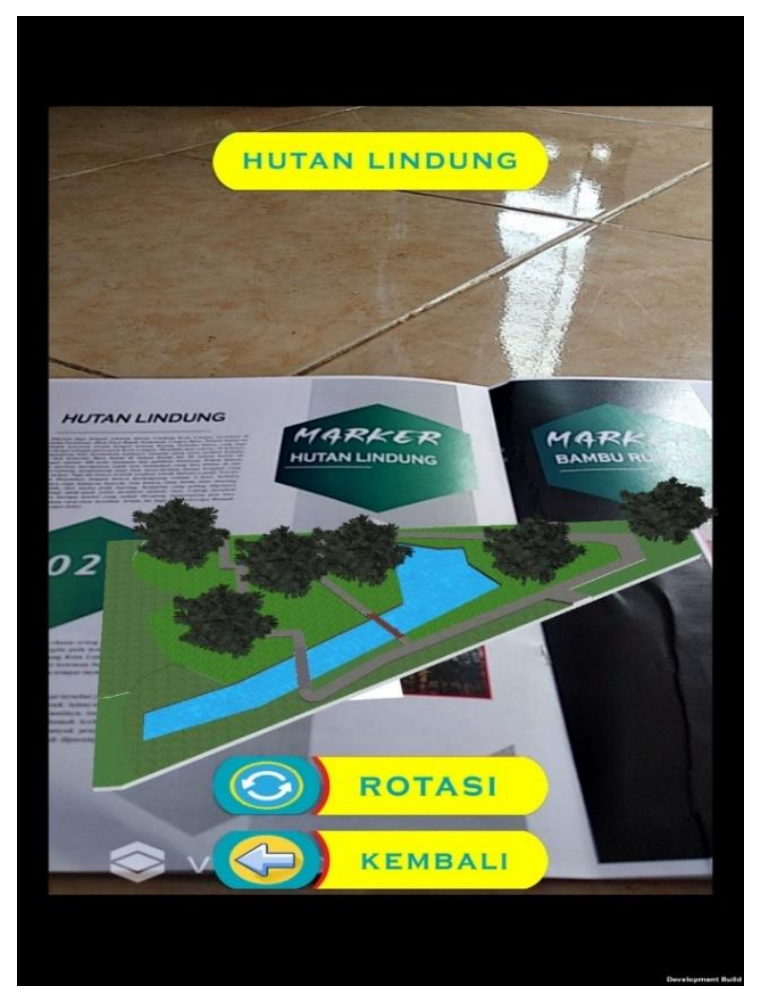

Gambar 9. Tampilan Kamera Objek Hutan Lindung

\subsection{Hasil Pengujian}

Untuk mengetahui efektifitas sistem AR pada Android, dilakukan uji coba pada beberapa device android berbeda , seperti Redmi 5+, Xiaomi Ml 
A1, Redmi Note5, dan Redmi note 8. Hasilnya sistem AR berhasil dijalankan dengan baik. Selain itu, dilakukan uji coba terhadap kemampuan kamera dalam mendeteksi marker berdasarkan jarak, dan posisi, dan pencahayaan.

Tabel 1. Pengujian Tracking Object

\begin{tabular}{cll}
\hline $\begin{array}{c}\text { Jarak } \\
(\mathbf{c m})\end{array}$ & \multicolumn{1}{c}{ Pencahayaan } & Tracking \\
\hline 10 & $\begin{array}{l}\text { Cahaya lampu } \\
\text { redup, gelap }\end{array}$ & Tidak berhasil \\
\hline 10 & $\begin{array}{l}\text { Sinar Matahari, } \\
\text { berawan }\end{array}$ & Berhasil \\
\hline 15 & $\begin{array}{l}\text { Cahaya lampu } \\
\text { redup, gelap }\end{array}$ & Berhasil \\
\hline 15 & $\begin{array}{l}\text { Sinar matahari, } \\
\text { berawan }\end{array}$ & Berhasil \\
\hline 20 & $\begin{array}{l}\text { Cahaya lampu } \\
\text { redup,gelap }\end{array}$ & Berhasil \\
\hline 20 & $\begin{array}{l}\text { Sinar matahari, } \\
\text { berawan }\end{array}$ & Berhasil \\
\hline 30 & $\begin{array}{l}\text { Cahaya lampu } \\
\text { redup,gelap }\end{array}$ & Berhasil \\
\hline 30 & $\begin{array}{l}\text { Sinar matahari, } \\
\text { berawan }\end{array}$ & Berhasil \\
\hline
\end{tabular}

Berdasarkan pengujian, terlihat bahwa proses tracking object berhasil dilakukan. Namun pada jarak $10 \mathrm{~cm}$ dan pencahayaan kurang, objek tidak berhasil di deteksi. Hasil terbaik pendeteksian mulai dari jarak $15 \mathrm{~cm}$ dengan pencahayaan berawan.

\section{Kesimpulan}

Augmented Reality (AR) berhasil dijalankan pada Andorid untuk media promosi objek wisata. AR berhasil menampilkan objek 3D berdasarkan marker objek. Hasil terbaik dalam menampilkan objek adalah mulai dari jarak $15 \mathrm{~cm}$ dengan kondisi pencahayaan berawan.

\section{Daftar Pustaka}

[1] S.R. Primadani, Mardiyono, Riyanto, "Analisis Strategi Pengembangan Pariwisata Daerah", Jurnal Administrasi Publik, vol 01 no 04.

[2] B.E. Kusuma, M.T.Tanzil, R.Cenderawan, "Perancangan Teknologi Augmented Reality Berbasis Android Dalam memberikan Petunjuk Navigasi Ruangan pada Universitas Pelita Harapan Medan, Jurnal , Vol.04, N0.01, 2019.

[3] Z.C.Rawis, V, Tulenan,B.A. Sugiarso, "Penerapan Augmented Reality Berbasis Android Untuk mengenalkan Pakaian Adat Tountemboan"E-Journal Teknik Informatika Vol.13, No.01.2018

[4] M.Z.Devita, S. Andryana, D.Hidayatullah, "Jurnal Media Informatika Budidarma, Volume 4 No 1, Januari 2020

[5] A.F. Masrura, M.F.Aditya, M.H.Isron, "Aplikasi Edukasi Berbasis Android Menggunakan Augmented Reality", Jurnal Keilmuan dan Aplikasi Teknik Informatika, pp 29-36, 2020.

[6] Mardiana, M.A. Muhammad, W.E.Sulistiono, G.P.Djausal, "Augmented Reality Pelacak Lokasi Wisata dengan AR Marker"Jurnal Teknologi Informasi dan Komputer (JTIIK)", vol 07 no 01, Februari 2020.

[7] H.Hamid, M.Jamil. "Perancangan Buku Interaktif Berbasis Augmented Reality Pada Pengenalan dan Pembelajaran Sejarah Terjadinya Pulau Maitara", Jurnal Informatika dan RPL", vol .1 No 2, September, 2019.

[8] A.Nugroho, B.A. Pramono, "Aplikasi Mobile Augmented Reality Berbasis Vuforia dan Unity Pada Pengenalan Objek 3D Dengan Studi Kasus Gedung M Universitas 
Semarang", Jurnal Transformatika, volume 14 no 02, 2017.

[9] Azhar, N.Fajri, "Pemanfaatan Augmeted Reality untuk Game "Ranger Target" FPS berbasis Android Menggunakan Unity dan Vuporia SDK" Fakultas Teknologi Informasi, Institute Teknologi Sepuluh November. 2011.

[10] B. Butchart, "Augmented Reality for Smartphone" Apress. 2011.

[11] I.Mustaqim, N.Kurniawan, "Pengembangan Media Pembelajaran Berbasis Augmented Reality" Jurnal Edukasi Elektro, Vol.1, No.1, Mei. 2017.

[12] A.Syahrin, M.E. Apriyani, S.Prasetyaningsih, "Analisis dan Implementasi Metode Marker Based Trackiing pada Augmented Reality Pembelajaran Buah-Buahan",Jurnal IImiah
Komputer dan Informatika"vol 05 no 01. 2016

[13] Maulana, Angga, W.Kusuma, "Aplikasi Augmented Reality Untuk Pembelajaran Tata Surya", Prosiding Seminar IImiah Komputer dan Sistem Intelijen. 2016.

[14] A.Sudianto, M.Sadali, "Penerapan Aplikasi Berbasis Android Untuk Ternak Ayam Petelur Sebagai Wadah Untuk Menghubungkan Pemilik Modal dengan Calon Peternak", Jurnal Informatika dan Teknologi, vol 04 no 01.Januari, 2021.

[15] N.Nurhidayati, A.Muliawan, M.Nur, "Pemanfaatan aplikasi Android Dalam Rancang Bangun Sistem Informasi Persebaran Indekos di Wilayah Pancor Kabupaten Lombok Timur", Jurnal Informatika dan Teknologi, vol 04 no 01,Januari, 2021 